\title{
Recovery of Scandium by Crystallization Techniques
}

\author{
Edward Michael Peters ${ }^{1} \cdot$ Şerif Kaya ${ }^{2} \cdot$ Carsten Dittrich $^{3} \cdot$ Kerstin Forsberg $^{1}$
}

Published online: 25 January 2019

(c) The Author(s) 2019

\begin{abstract}
Bauxite residues, i.e., red mud, can be processed to recover various valuable end products, while reducing the environmental impact of the waste. Scandium is one of the valuable elements in bauxite residues. It is possible to extract and enrich scandium from red mud by leaching and solvent extraction. Scandium can then be recovered from the pregnant strip liquor by crystallization. Different crystallization techniques can be used to generate the supersaturation required for scandium to crystallize out as a salt. In the present study, the crystallization of an ammonium scandium fluoride phase by cooling and antisolvent crystallization techniques is presented. Cooling crystallization gave a low yield of ammonium scandium hexafluoride, $\left(\mathrm{NH}_{4}\right)_{3} \mathrm{ScF}_{6}$, below $50 \%$ at the lowest temperature of $1{ }^{\circ} \mathrm{C}$ investigated. Antisolvent crystallization using ethanol gave almost complete recovery with precipitation efficiency greater than $98 \%$ for an ethanol-to-strip liquor volumetric ratio of 0.8. Solubility data of $\left(\mathrm{NH}_{4}\right)_{3} \mathrm{ScF}_{6}$ under different temperatures and in different ethanol-strip liquor mixtures is herein presented. The product obtained by antisolvent crystallization had very minute crystals $(<2 \mu \mathrm{m})$ due to the high supersaturation generated upon adding ethanol to the strip liquor, while it was easier to obtain larger crystals by cooling crystallization. Fe and Ti impurities were detected in the solid product, and an insight into the mechanism of impurity uptake is discussed.
\end{abstract}

Keywords Ammonium scandium hexafluoride · Cooling crystallization · Antisolvent crystallization · Purity · Solubility · Impurity incorporation

\section{Introduction}

Scandium is a precious metal that has increasingly found use in many applications, which include production of high strength aluminum alloys for aircraft parts and use in solid oxide fuel cells (SOFCs) [1]. Scandium, in concentrations not exceeding $0.2 \mathrm{wt} \%$, increases the strength to weight ratio of aluminum alloys and allows welding without loss of strength, and about $90 \%$ of scandium production is currently used in SOFCs [2]. Due to these developments, there has been an increasing demand for this metal [3], yet there are limited commercially exploitable reserves $[1,4$,

The contributing editor for this article was Yiannis Pontikes.

Kerstin Forsberg

kerstino@kth.se

1 Department of Chemical Engineering, KTH Royal Institute of Technology, 100-44 Stockholm, Sweden

2 Mining Engineering Department, Middle East Technical University, 06800 Ankara, Turkey

3 MEAB Chemie Technik GmbH, 52068 Aachen, Germany
5]. Scandium is widely dispersed in the Earth's crust $[5,6]$ at a concentration of about $22 \mathrm{ppm}$, comparable to that of cobalt and greater than that of lead and other common metals [7]. Currently, there is no scandium production in Europe and production occurs in China (66\%), Russia (26\%) and Ukraine (7\%) [8]. Consequently, scandium has been listed as a critical raw material by the EU and the US government $[8,9]$.

The commercially viable option is to recover scandium from waste streams of other metallurgical processing industries. These include bauxite residue $(60-120 \mathrm{ppm} \mathrm{Sc})$ from the aluminum industry, acid waste from $\mathrm{TiO}_{2}$ pigment industry as well as lateritic $\mathrm{Ni-Co}$ processing $[1,10,11]$. A range of integrated separation techniques including leaching and solvent extraction can be employed to recover Sc from these waste streams $[5,7,10,11]$. A solid Sc phase can then be crystallized from the concentrated strip liquor stream. In crystallization under cooling conditions, supersaturation is achieved by cooling a solution below its saturation temperature, whereas in antisolvent crystallization, supersaturation is induced by adding a suitable soluble solvent to the 
solution, thereby reducing the solubility of the stable salt in the resultant solvent matrix [12].

The current state-of-the-art in the recovery of scandium from metallurgical waste streams involves leaching to extract scandium from the waste stream, e.g., bauxite residue [13-15]. Solvent extraction is then employed to extract Sc from the pregnant leach solution (PLS) using an organic solvent, followed by stripping of Sc back into the aqueous phase [11, 16-18]. Sc is then recovered by precipitation as the hydroxide or oxalate salt $[19,20]$, which are calcined at temperatures of $700-800{ }^{\circ} \mathrm{C}$ to obtain scandium oxide [21]. The oxide is then fluorinated using hydrofluoric (HF) acid to obtain $\mathrm{ScF}_{3}$ [22], which is the precursor for the production of $\mathrm{Sc}$ and $\mathrm{Al}-\mathrm{Sc}$ alloys.

In the process considered herein, an $\mathrm{NH}_{4} \mathrm{~F}$ solution is used to strip Sc from the organic phase, and $\mathrm{Sc}$ is then recovered as $\left(\mathrm{NH}_{4}\right)_{3} \mathrm{ScF}_{6}$ by crystallization. This intermediate product can be calcined at temperatures between 340 and $350{ }^{\circ} \mathrm{C}$ to obtain $\mathrm{ScF}_{3}$ [23]. $\mathrm{ScF}_{3}$ can be used for the direct production of scandium metal and $\mathrm{Sc}-\mathrm{Al}$ alloys by metallothermic reduction [24]. This processing route is favorable from sustainability and economic perspectives since it eliminates the direct use of $\mathrm{HF}$ acid in the production of $\mathrm{ScF}_{3}$ and calcination of the intermediate product, $\left(\mathrm{NH}_{4}\right)_{3} \mathrm{ScF}_{6}$, is accomplished at lower temperatures, hence at low-energy and with low-cost benefits. In addition, the processing route has fewer steps since fluoride salts can be directly crystallized from solution. For antisolvent crystallization, the high quantities of the antisolvent required can be offset by the fact that the antisolvent can be recovered in a separate distillation process and reused in the precipitation stage.

Scandium can be precipitated in various phases, e.g., hydroxide, oxalate, phosphate, carbonate, and fluoride. The precipitation method commonly used is the addition of a chemical reagent to a solution containing Sc to precipitate the Sc salt. For instance, addition of oxalic acid results in precipitation of scandium oxalate [19], while $\left(\mathrm{NH}_{4}\right)_{2} \mathrm{HPO}_{4}$ reagent results in $\mathrm{ScPO}_{4}$ precipitation [25]. Addition of $\mathrm{NaF}$ solutions in different concentrations to an $\mathrm{NH}_{4} \mathrm{HF}_{2}$ solution containing Sc can result in precipitation of a mixture of salts namely, $\mathrm{ScF}_{3}, \mathrm{Na}_{3} \mathrm{ScF}_{6}$ and $\mathrm{Na}\left(\mathrm{NH}_{4}\right)_{2} \mathrm{ScF}_{6}$ in different proportions [26]. For antisolvent crystallization, the choice of a suitable solvent is dependent on several factors including ionic speciation in the new solvent matrix [27]. The solubility of metal salts is usually decreased upon the addition of an alcohol (antisolvent) to an aqueous solution. This occurs since most inorganic metal salts have lower solubility in alcohol than in water. However, in a previous study, it was found that formation of chloro-complexes was enhanced in aqueous-alcohol solvent mixtures, and the chloride salts did not precipitate [27].

The stability constants of complexes are mainly available for purely aqueous systems and not for solvent mixtures. The stability constants of Sc fluoride complexes [28] as well as the solubility product of $\mathrm{ScF}_{3}$ [29] in aqueous solutions have been published. In addition, the solubilities of $\mathrm{ScF}_{3}$ and $\left(\mathrm{NH}_{4}\right)_{3} \mathrm{ScF}_{6}$ have been determined in HF-dosed solutions [30]. Various crystalline phases which include $\mathrm{ScF}_{3}, \mathrm{NH}_{4} \mathrm{ScF}_{4},\left(\mathrm{NH}_{4}\right)_{5} \mathrm{Sc}_{3} \mathrm{~F}_{14}$, $\mathrm{NH}_{4} \mathrm{Sc}_{3} \mathrm{~F}_{10},\left(\mathrm{NH}_{4}\right)_{2} \mathrm{Sc}_{3} \mathrm{~F}_{11}$, and the $\alpha$ - and $\beta$ - polymorphs of $\left(\mathrm{NH}_{4}\right)_{3} \mathrm{ScF}_{6}$ have been reported for the $\mathrm{ScF}_{3}-\mathrm{NH}_{4} \mathrm{~F}$ system $[26,31] . \beta-\left(\mathrm{NH}_{4}\right)_{3} \mathrm{ScF}_{6}$ was identified as the most stable phase in the $\mathrm{ScF}_{3}-\mathrm{NH}_{4} \mathrm{~F}$ system at high fluoride concentrations at temperatures below $90{ }^{\circ} \mathrm{C}[31,32]$. This phase was observed to decompose thermally at temperature ranges of $260-290{ }^{\circ} \mathrm{C}$ and $340-350{ }^{\circ} \mathrm{C}$ to $\mathrm{NH}_{4} \mathrm{ScF}_{4}$ and $\mathrm{ScF}_{3}$, respectively $[23,32]$.

In the current study, the starting solution is a synthetic pregnant strip liquor stream containing about $0.2 \mathrm{wt} \% \mathrm{Sc}$ and some metal impurities (Fe, $\mathrm{Ti}$ ) in an $\mathrm{NH}_{4} \mathrm{~F}$ solution matrix. The solution matrix is basically the stripping solvent employed in the upstream solvent extraction process. This paper reports on the preliminary evaluation of the technical feasibility of recovering $\mathrm{Sc}$ from the strip liquor using cooling and antisolvent crystallization. A comparison of the two techniques is drawn with regards to product quality and yield. An investigation into the mechanism of impurity uptake by the solid product obtained by antisolvent crystallization is also presented.

\section{Methodology}

\section{Strip Liquor Preparation}

Synthetic strip liquors were prepared by MEAB Chemie Technik GmbH laboratory. The starting solution in the preparation of the strip liquors was a scandium sulphate solution containing ca. $2640 \mathrm{mg} / \mathrm{L} \mathrm{Sc}$. The solvent extraction conditions were chosen so as to obtain a strip liquor that was undersaturated with respect to ammonium scandium hexafluoride. This scandium enrichment process can be employed to any feed material with a considerable scandium concentration, e.g., bauxite residue, and the final strip liquor composition depends on the initial composition of the feed material as well as the extent of coextraction of impurity metals. $\mathrm{Sc}_{2}\left(\mathrm{SO}_{4}\right)_{3} \cdot 6 \mathrm{H}_{2} \mathrm{O}$ of purity ca. $99.9 \%$ purchased from Richest Group, China was used for solution preparation. In the second case, $\mathrm{TiOSO}_{4}$ and $\mathrm{Fe}_{2}\left(\mathrm{SO}_{4}\right)_{3}$ salts of purities ca. $99.7 \%$ and $99.9 \%$ were added to the starting solution in order to obtain a solution containing $\mathrm{Ti}$ and $\mathrm{Fe}$ impurities. The synthetic solutions were then subjected to solvent extraction using D2EHPA, purchased from Lanxess, Germany, at an organic to aqueous volumetric ratio of 1 . The loaded organic phase was 
Table 1 Strip liquor compositions and $\mathrm{pH}$ values

\begin{tabular}{lllll}
\hline $\begin{array}{l}\text { Strip liquor } \\
\text { (SL) }\end{array}$ & $\mathrm{pH}$ & $\mathrm{Sc}(\mathrm{g} / \mathrm{L})$ & $\mathrm{Fe}(\mathrm{g} / \mathrm{L})$ & $\mathrm{Ti}(\mathrm{g} / \mathrm{L})$ \\
\hline (A) & 5.61 & 2.24 & - & - \\
(B) & 5.67 & 2.52 & 0.12 & $3.2 \times 10^{-4}$ \\
(C) & 5.68 & 2.09 & 0.08 & 0.41 \\
\hline
\end{tabular}

then stripped using a $3 \mathrm{~mol} / \mathrm{L} \mathrm{NH}_{4} \mathrm{~F}$ solution at an aqueous to organic volumetric ratio of 1 in order to concentrate $\mathrm{Sc}$ in the aqueous phase. Coextraction of $\mathrm{Fe}$ and Ti impurities occurred and the composition of the strip liquors is shown in Table 1.

\section{Materials}

Table 1 shows the $\mathrm{pH}$ and average compositions of the strip liquors in a $3 \mathrm{~mol} / \mathrm{L} \mathrm{NH}_{4} \mathrm{~F}$ solution.

An Orion Star A211 pH meter was used for $\mathrm{pH}$ measurements under ambient conditions (ca. $20{ }^{\circ} \mathrm{C}$ ) and the total metal ion concentrations were determined by ICP-OES (ThermoScientific iCAP 7000 series). The phase of the dried precipitates was determined using a SIEMENS powder X-Ray Diffractometer D5000. A JEOL JSM-6490LV Scanning Electron Microscope (SEM) was used to capture images of the solid precipitates obtained by cooling crystallization. A Phillips SL 30 Environmental Scanning Electron Microscope (ESEM) equipped with EDS was used to capture images of the solid precipitates obtained by antisolvent crystallization and to analyze the surface composition of the solids.

For antisolvent crystallization experiments, reagent grade absolute ethanol $(99.94 \% \mathrm{v} / \mathrm{v})$ was used as the antisolvent (AS). A temperature-controlled water bath circulator was used to maintain the desired temperature for all experiments by means of a PT100 temperature sensor with an accuracy of $\pm 0.01{ }^{\circ} \mathrm{C}$.

\section{Procedure}

A methodology was developed to investigate the crystallization behavior of the strip liquor and to determine which solid phase was most stable under various operating conditions, that is different temperatures and different AS dosages.

\section{Cooling Crystallization}

A sample of $100 \mathrm{~g}$ (ca. $95 \mathrm{~mL}$ ) of strip liquor (A) was cooled at a rate of $0.5{ }^{\circ} \mathrm{C}$ per minute, and the first solid precipitate was observed at $13{ }^{\circ} \mathrm{C}$. The liquor was maintained at $13{ }^{\circ} \mathrm{C}$ under stirring at $600 \mathrm{rpm}$ for a period of $72 \mathrm{~h}$ to attain equilibrium. Initially, supernatant samples were collected on a daily basis, and it was predetermined that $72 \mathrm{~h}$ was sufficient to achieve equilibration. At the end of the experiment, a $2 \mathrm{~mL}$ supernatant sample was obtained by means of a $0.2-\mu \mathrm{m}$ polypropylene syringe filter, and the remaining suspension was filtered under vacuum using a $0.22 \mu \mathrm{m}$ PVDF membrane filter. The total concentration of metal ions was determined using ICP-OES. The solid precipitate was subjected to natural evaporation until its weight remained appreciably constant. A solid sample was analyzed by powder XRD. SEM analyses were conducted to obtain crystal morphology. The supernatant obtained after filtration was then maintained at a lower temperature for another $72 \mathrm{~h}$ and the above procedure was repeated for each temperature investigated. Operating temperatures investigated were 13 , $10,8,6,3$, and $1{ }^{\circ} \mathrm{C}$, respectively.

\section{Antisolvent Crystallization}

Absolute ethanol was added to $50 \mathrm{~mL}$ of strip liquor (B) to achieve ethanol-to-strip liquor volumetric ratios of 0.2 to 1.4 at intervals of 0.2 . The resulting suspension was then maintained at $25{ }^{\circ} \mathrm{C}$ under stirring at $600 \mathrm{rpm}$ for $72 \mathrm{~h}$ to achieve equilibration. The solid precipitate obtained was filtered off and then washed using $10 \mathrm{~mL}$ of absolute ethanol and analyzed by SEM to obtain crystal morphology. Sample collection and analyses of the supernatant and solid samples were conducted as outlined above. Strip liquor (C) containing higher levels of Ti was also used under similar conditions at ratios of 0.2 and 1.4 to investigate the behavior of Ti during precipitation. All experiments were conducted in triplicate to ascertain reproducibility. In both cooling and antisolvent crystallization, the total Sc concentration obtained by ICPOES analyses after $72 \mathrm{~h}$ of equilibration was taken to be the solubility determined from the supersaturated state.

A separate set of experiments was conducted by the same method using strip liquor (C) at volumetric ratios of $0.2,0.8$ and 1.4 , with a residence time of $1 \mathrm{~h}$, in an attempt to determine the mechanism of impurity uptake in the solid product. The solid precipitates were analyzed by ESEM-EDS to determine the surface elemental composition.

\section{Results and Discussion}

\section{Solid Phase}

The stable phase obtained at all temperatures in the range $1-13{ }^{\circ} \mathrm{C}$ for cooling crystallization and at $25{ }^{\circ} \mathrm{C}$ for antisolvent crystallization at different ethanol-to-strip liquor ratios was determined by powder XRD to be ammonium scandium hexafluoride $\left(\mathrm{NH}_{4}\right)_{3} \mathrm{ScF}_{6}$ of monoclinic structure, PDF card 00-040-0595 [31, 33], see Fig. 1. 


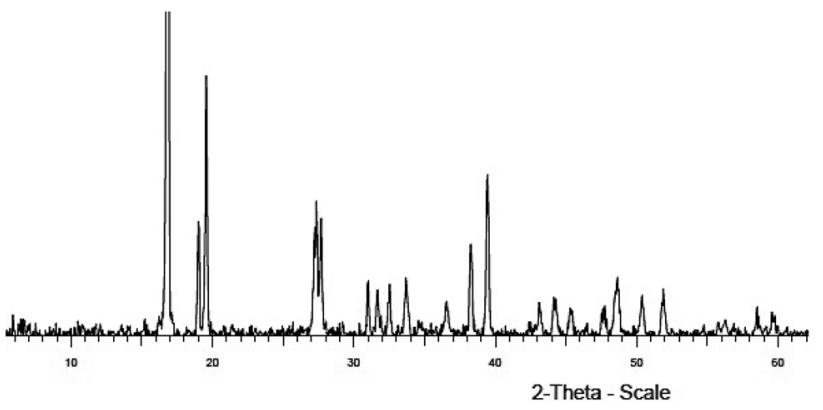

Fig. 1 XRD pattern obtained for the solid product

\section{Solubility}

The solubility was calculated for the phase $\left(\mathrm{NH}_{4}\right)_{3} \mathrm{ScF}_{6}$ on the basis of total Sc concentration obtained by ICP-OES. Figure $2 \mathrm{a}$ shows the solubility in $\mathrm{g} / \mathrm{L}$ of $\left(\mathrm{NH}_{4}\right)_{3} \mathrm{ScF}_{6}$ at different temperatures in the range $1-13{ }^{\circ} \mathrm{C}$ in a $3 \mathrm{~mol} / \mathrm{L}$ $\mathrm{NH}_{4} \mathrm{~F}$ strip liquor (A). Figure $2 \mathrm{~b}$ shows the solubility data obtained using strip liquors (B) and (C) at varying ethanolto-strip liquor volumetric ratios for antisolvent crystallization at $25^{\circ} \mathrm{C}$.

As expected and shown in Fig. 2a, the solubility decreased almost linearly with the decreasing temperature.
It can be noted that complete recovery of the salt is practically impossible due to the solubility limitation at the lowest temperature of $1{ }^{\circ} \mathrm{C}$ investigated. The solubility data obtained is indispensable in conducting controlled cooling crystallization experiments.

Figure $2 \mathrm{~b}$ shows that the solubility decreased asymptotically with the increasing amount of ethanol added almost approaching zero at ethanol-to-strip liquor volumetric ratios above 1 . This means that a high recovery close to $100 \%$ of the stable phase can be obtained as depicted in Fig. $3 \mathrm{~b}$. The solubilities of $\left(\mathrm{NH}_{4}\right)_{3} \mathrm{ScF}_{6}$ obtained using strip liquor (C) at ratios 0.2 and 1.4 were similar to the data obtained for strip liquor (B). It was also observed that the $\mathrm{pH}$ of the mixtures increased almost linearly between 6.1 and 6.8 with the increasing quantity of ethanol.

\section{Yield}

Figures $3 \mathrm{a}$ and $\mathrm{b}$ show the cumulative yield (\%) obtained during cooling and antisolvent crystallization, respectively. Equation 1 was used to calculate the yield for cooling crystallization $\left(\mathrm{Y}_{\mathrm{c}}, \%\right)$, where, $\mathrm{C}_{\mathrm{i}}$ is the initial Sc concentration in the strip liquor and $\mathrm{C}_{\mathrm{s}}$ is the solubility at the specific temperature.
Fig. 2 Solubility of $\left(\mathrm{NH}_{4}\right)_{3} \mathrm{ScF}_{6}$ phase: $\mathbf{a}$ in $3 \mathrm{~mol} / \mathrm{L} \mathrm{NH}_{4} \mathrm{~F}$ strip liquor solution at different temperatures, $\mathbf{b}$ in different ethanolto-strip liquor ratios at $25^{\circ} \mathrm{C}$
Fig. 3 Cumulative yield \%: a cooling crystallization of SL (A), $\mathbf{b}$ antisolvent crystallization of SL (B)
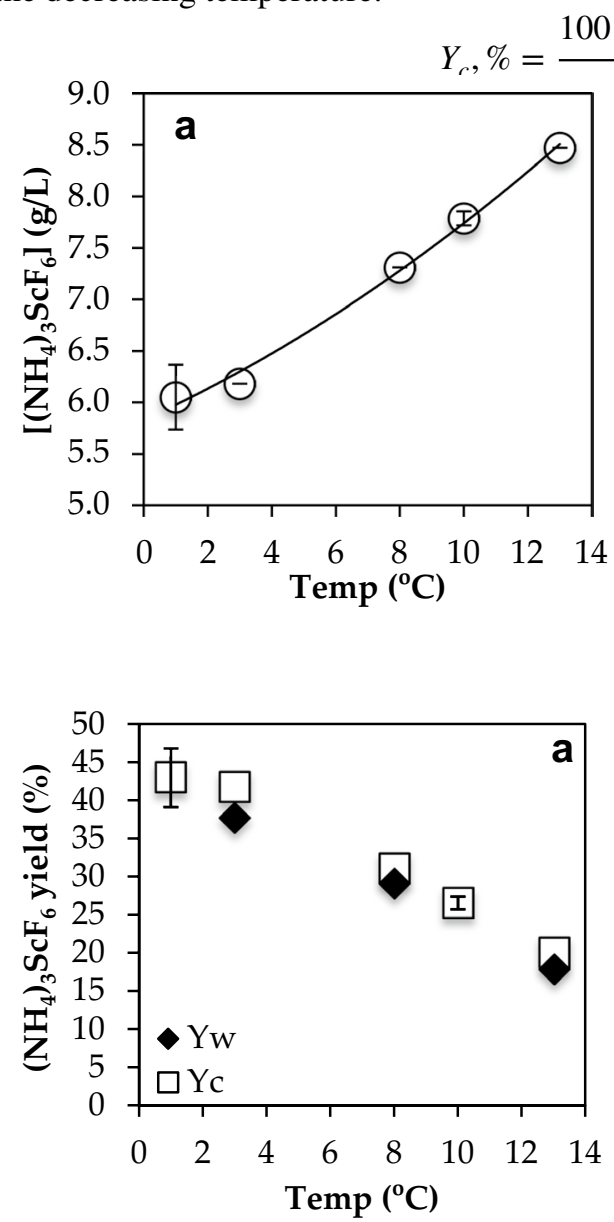
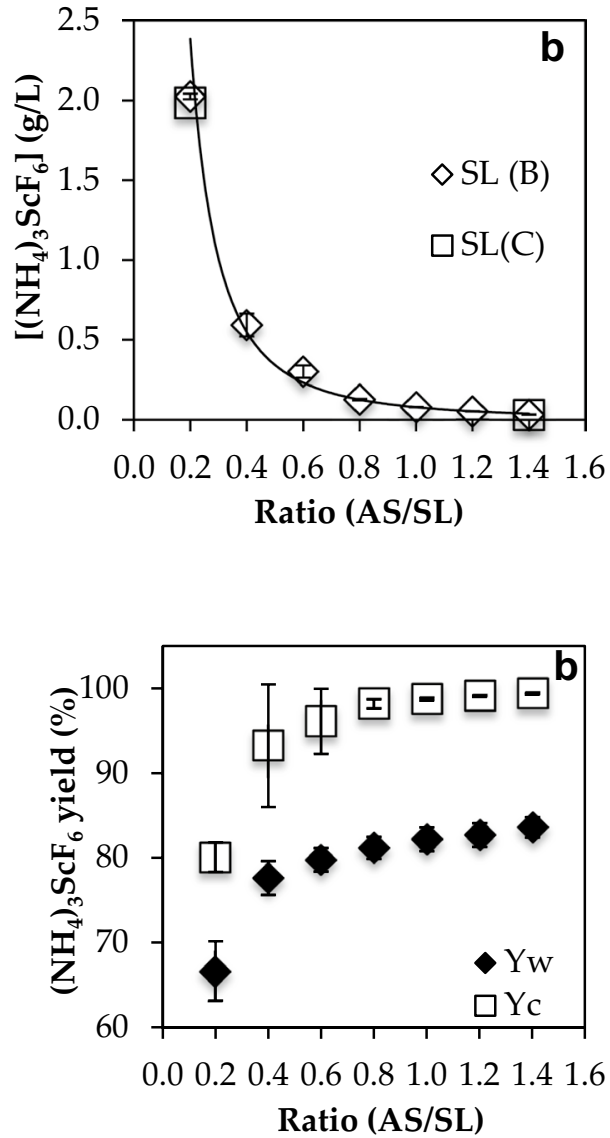

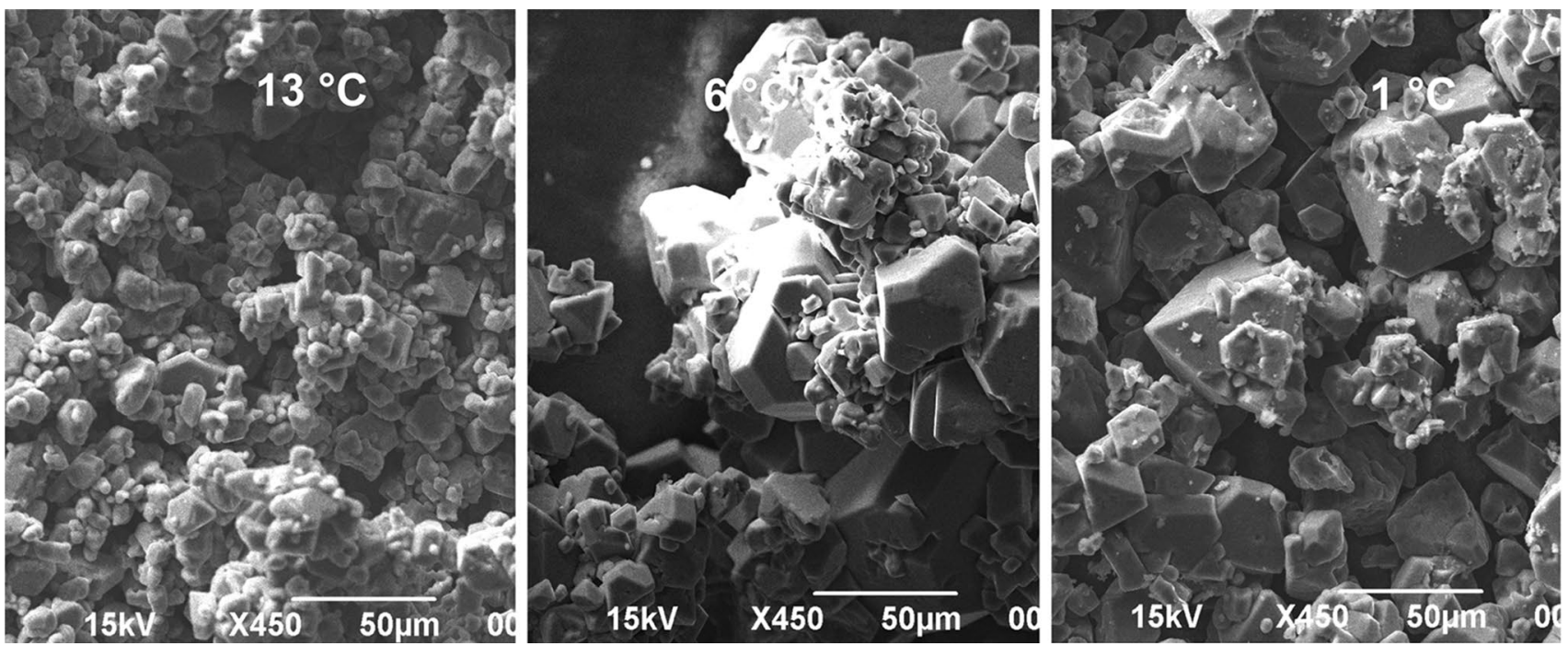

Fig. 4 Morphology of the precipitates obtained by cooling crystallization at 13,6 and $1{ }^{\circ} \mathrm{C}$

For antisolvent crystallization, the concentrations in Eq. 1 were multiplied by the respective solution volumes due to significant changes in volume upon addition of ethanol. It should be noted that the volumes are not additive upon adding ethanol to the strip liquor. The densities of the new solvent mixtures were determined to facilitate a correct mass balance. The yield was also determined by weighing the dry solid samples, $\mathrm{Y}_{\mathrm{w}}$. During cooling crystallization, the cumulative yield increased with the decreasing operating temperature due to reduction in solubility, see Fig. 3a. It can be noted that the highest yield obtained at $1{ }^{\circ} \mathrm{C}$ was below $50 \%$.

It is recommended to investigate cooling crystallization at subzero temperatures to determine if the yield would increase remarkably or asymptotically. However, employing subzero temperatures to the dilute strip liquor could result in formation of large quantities of ice, which could entrap all the salt precipitate. This could be uneconomical given that the $\mathrm{Sc}$ content to be recovered is only a minute quantity. Likewise, Fig. $3 \mathrm{~b}$ shows the cumulative yield (\%) obtained during antisolvent crystallization. High yields above $65 \%$ were obtained even at the lowest mixing ratio of 0.2 . It can be noted that a ratio of 0.8 is optimal, and any further increase in ratio does not result in significant increase in the yield. Although huge quantities of ethanol are required, the increase in raw material costs is counterbalanced by the fact that the ethanol can be recovered by distillation and reused in the process. The data in Fig. 3 also indicate that combining the two crystallization techniques and conducting antisolvent crystallization at a lower temperature could improve the product yield while reducing the antisolvent required.

In both cases, the yield obtained by weighing the solid $\left(\mathrm{Y}_{\mathrm{w}}\right)$ is lower than the calculated yield $\left(\mathrm{Y}_{\mathrm{c}}\right)$. This can be attributed to dissolution of the solid product during the filtration and washing stages. This difference is more pronounced for antisolvent crystallization probably due to the minute crystals obtained as shown in Fig. 5, hence low filterability and greater dissolution extent. In addition, part
Fig. 5 Morphology of the precipitates obtained by antisolvent crystallization at $25^{\circ} \mathrm{C}$ : a ratio 0.2 and $\mathbf{b}$ ratio 1.4
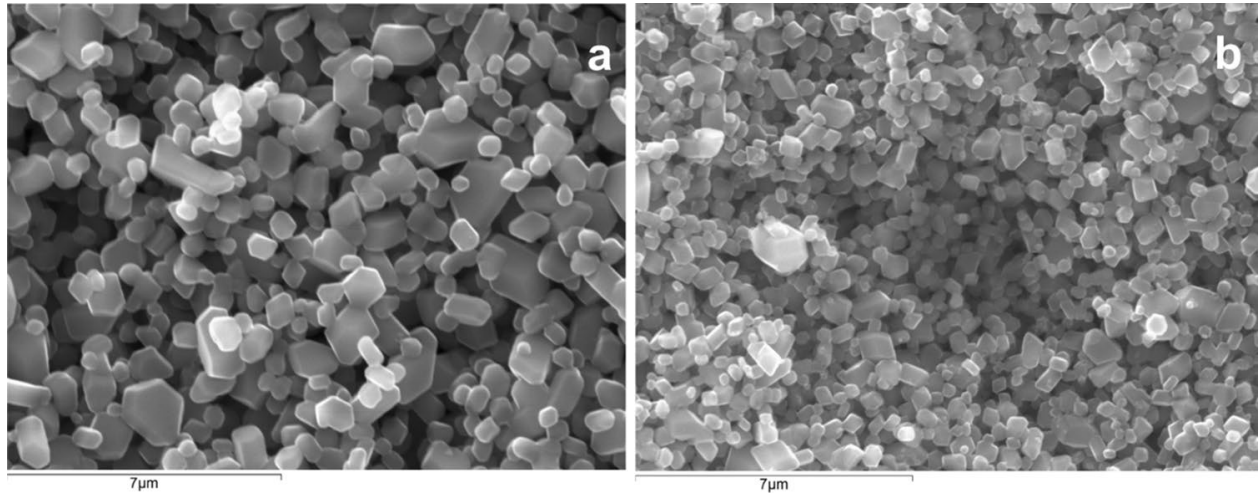
of the crystals could have passed through the membrane filter.

\section{Morphology and Crystal Size}

Figure 4 shows the morphology of the crystals obtained by cooling crystallization at 13,6 and $1{ }^{\circ} \mathrm{C}$. The crystals obtained by cooling crystallization had regular prismatic shapes indicating that a highly crystalline $\left(\mathrm{NH}_{4}\right)_{3} \mathrm{ScF}_{6}$ product can be obtained. The product obtained at $13{ }^{\circ} \mathrm{C}$ had numerous fines of sizes approximately $10 \mu \mathrm{m}$ probably due to primary nucleation. Larger crystals were observed for the lower temperatures possibly due to carry-over of some fine crystals during filtration, which in turn, induced secondary nucleation in subsequent lower temperature experiments.

The effect of the thermal history of the solution on inducing nucleation at a higher temperature, hence lower supersaturation could also play a role [12]. When a solution is cooled to supersaturation resulting in nucleation, the thermal treatment, that is, the heating temperature and duration that the solution undergoes during dissolution of crystals has an effect on the metastable zone width, induction time, hence nucleation upon cooling the same solution again. In general, it was hypothesized that during the initial dissolution phase of crystals, the solution retains some molecular assemblies that promote nuclei formation at a reduced supersaturation $[34,35]$. A similar phenomenon could have occurred upon filtration and washing of the solid product resulting in molecular assemblies passing through the membrane filter into the solution that was cooled to lower temperatures in subsequent experiments. Crystals of sizes approaching 50 $\mu \mathrm{m}$ were observed at 6 and $1{ }^{\circ} \mathrm{C}$. By designing a seeded cooling crystallization process, there is potential to obtain even larger product crystals.

Figure 5 shows the morphology of crystals obtained from strip liquor (C) by antisolvent crystallization at $25{ }^{\circ} \mathrm{C}$ at ethanol-to-strip liquor ratios of 0.2 and 1.4, respectively.

For antisolvent crystallization, discrete minute crystals of defined shapes and sizes of approximately $<2 \mu \mathrm{m}$ were observed. The fine crystals were attributed to a very high supersaturation generated upon adding the ethanol to the strip liquor, resulting in dominance of nucleation over crystal growth. The crystals decreased in size with the increasing ethanol content due to the increasing supersaturation. The ethanol was added wholly and it was observed that crystallization was instantaneous throughout the entire solution volume due to high bulk supersaturation. For this reason, it is very imperative to control the rate of supersaturation generation in order to obtain larger crystals. This can be accomplished by controlling the rate of addition of the antisolvent, coupled with adequate agitation to prevent high local supersaturation at the point of mixing. Seeding can also improve the crystal sizes since it promotes crystal growth. If this control is mastered, antisolvent crystallization serves as a better alternative for the recovery of $\left(\mathrm{NH}_{4}\right)_{3} \mathrm{ScF}_{6}$ from the strip liquor, since higher yields are obtained with possible reuse of the ethanol solvent for a cost effective operation.

\section{Impurity Incorporation}

Figure 6 shows the impurity (Ti, $\mathrm{Fe}$ ) content in the solid product obtained from strip liquor (C) by antisolvent crystallization as determined by ICP-OES after dissolving the solid samples.

The Fe and Ti contents in the solid product increased upon increasing the AS/SL ratio from 0.2 to 1.4. The solid product purities obtained at ratios 0.2 and 1.4 were 98.9 and $98.7 \%$, respectively. After performing a mass balance, it was observed that the concentration of $\mathrm{Fe}$ in the supernatant decreased by more than $90 \%$ with the increasing AS concentration, while the concentration of Ti remained fairly constant. The precipitation percentages of $\mathrm{Fe}$ were computed by Eq. 2, where $\mathrm{P}$ is the precipitation percentage, subscript 'Me' refers to the metal impurity ( $\mathrm{Fe}), \mathrm{C}_{\mathrm{Me}, \mathrm{i}}$ and $\mathrm{C}_{\mathrm{Me}, \mathrm{f}}$ are the initial and final concentrations of the metal in solution, and $V_{i}$ and $V_{f}$ are the initial and final volumes, respectively.

$P_{M e}=\frac{C_{M e, i} \cdot V_{i}-C_{M e, f} \cdot V_{f}}{C_{M e, i} \cdot V_{i}} \times 100$

The precipitation percentage of Fe was high (98.4 and $98.2 \%$ at an AS/SL ratio of 0.8 and 1.4, respectively), but since the initial concentration in the strip liquor is quite low, this does not translate into very high impurity concentrations in the solid product. The Fe and Ti detected in the solid phase could have either coprecipitated as separate phases (e.g., $\left(\mathrm{NH}_{4}\right)_{3} \mathrm{FeF}_{6}$ and $\left.\left(\mathrm{NH}_{4}\right)_{2} \mathrm{TiF}_{6}\right)$ and/or have been incorporated in the $\left(\mathrm{NH}_{4}\right)_{3} \mathrm{ScF}_{6}$ crystal lattice. The solubilities of

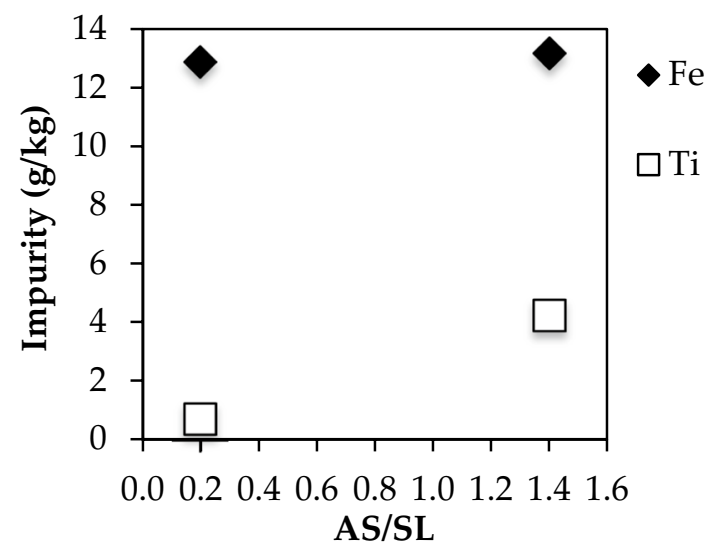

Fig. 6 Impurity content in the solid product at AS/SL ratios 0.2 and 1.4 
the $\mathrm{Fe}$ and $\mathrm{Ti}$ phases are unknown under the experimental conditions. The only phase detected by Powder XRD was $\left(\mathrm{NH}_{4}\right)_{3} \mathrm{ScF}_{6}$ (Fig. 1).

Further investigations were conducted to gain an insight into the mechanism of impurity uptake into the solid product. Table 2 shows the average $\mathrm{Ti}$ and $\mathrm{Fe}$ concentrations in the solid precipitate, in wt $\%$, as determined by EDS analyses at different ratios for two sets of experiments.

The results are similar to the ones obtained by ICP-OES (after dissolving the solid sample and analyzing the concentrations in the liquid phase) presented in Fig. 6 except that the $\mathrm{Fe}$ content decreased slightly with the increasing ethanol-to-strip liquor ratio. Appendix A shows the EDS analysis for one of the experiments conducted at a ratio of 0.8 . The EDS analyses revealed that $\mathrm{Fe}$ was homogeneously distributed throughout the solid surface layer, while Ti was only detected in lower concentrations at a few specific regions. The even distribution of $\mathrm{Fe}$ in the surface layer could imply that $\mathrm{Fe}$ was incorporated into the $\left(\mathrm{NH}_{4}\right)_{3} \mathrm{ScF}_{6}$ crystal lattice substituting Sc ions proportionately, otherwise if Fe had precipitated as separate crystals homogeneously spread in the solid product, it would have been expected that the Fe content would be much higher than the percentages detected by EDS. The ionic radii of $\mathrm{Sc}^{3+}$ and $\mathrm{Fe}^{3+}$ are 74.5 and $64.5 \mathrm{pm}$, respectively [36]. The ionic radii of $\mathrm{Ti}^{4+}$ is $60.5 \mathrm{pm}$ [36], and $\mathrm{Ti}^{4+}$ is less likely to compete with $\mathrm{Sc}^{3+}$ ions due to the fact that Ti binds strongly to oxygen exhibiting the characteristic titanyl bond [37]. Ti was detected only at a few points, where it was detected together with $\mathrm{Sc}$ and $\mathrm{Fe}$ indicating that it could have precipitated as a mixed phase.

In the downstream final refinement stage of Sc by sublimation, impurities that have comparable or higher vapor pressure than $\mathrm{Sc}$ (e.g., $\mathrm{Fe}$ ) are difficult to remove, while it is easier to separate Ti due to its lower vapor pressure at the sublimation temperatures employed $\left(>2000{ }^{\circ} \mathrm{C}\right)$. Therefore, it would be desirable to further reduce the Fe content in the solid product in order to obtain a purer final scandium metal. There is potential to improve the purity of the product by controlling the rate of ethanol addition and seeding as shown in a preliminary study in our lab [38].

Table 2 Impurity concentrations (detected by ESEM-EDS)

\begin{tabular}{lll}
\hline Ratio & Fe (wt\%) & Ti (wt\%) \\
\hline 0.2 & $1.39 \pm 0.02$ & $0.22 \pm 0.05$ \\
0.8 & $1.25 \pm 0.07$ & $0.51 \pm 0.05$ \\
1.4 & $1.14 \pm 0.05$ & $0.39 \pm 0.00$ \\
\hline
\end{tabular}

\section{Conclusions and Recommendations}

The technical feasibility of recovering Sc from strip liquor as $\left(\mathrm{NH}_{4}\right)_{3} \mathrm{ScF}_{6}$ using cooling and antisolvent crystallization techniques has been proven. While cooling crystallization produced a precipitate with larger crystal sizes, its applicability is limited by the higher product solubility at the lowest temperature investigated with $\left(\mathrm{NH}_{4}\right)_{3} \mathrm{ScF}_{6}$ yield less than $50 \%$. On the other hand, antisolvent crystallization produced a very high yield of the solid product, but with very minute crystals $(\sim 2 \mu \mathrm{m})$, which have an undesirable impact on the filtration and washing efficiency. However, a tradeoff has to be considered between better filtration efficiency and high efficiency in downstream processing with respect to crystal size. Through EDS analyses, it was postulated that $\mathrm{Fe}^{3+}$ ions were incorporated in the $\left(\mathrm{NH}_{4}\right)_{3} \mathrm{ScF}_{6}$ crystal lattice due to almost comparable ionic radii of $\mathrm{Sc}^{3+}$ and $\mathrm{Fe}^{3+}$ ions resulting in homogeneous distribution of $\mathrm{Fe}$ in the crystals. Ti was only detected at a few specific regions on the solid surface in minute quantities. It is recommended to conduct seeded and supersaturation-controlled experiments in order to improve crystal size and purity, and also conduct antisolvent crystallization experiments at lower temperatures to improve yield and reduce the quantity of the antisolvent required.

Acknowledgements This project has received funding from the European Union's Horizon 2020 research and innovation program under grant agreement No. 730105-SCALE.

\section{Compliance with Ethical Standards}

Conflicts of interest On behalf of all authors, the corresponding author states that there is no conflict of interest.

Open Access This article is distributed under the terms of the Creative Commons Attribution 4.0 International License (http://creativeco mmons.org/licenses/by/4.0/), which permits unrestricted use, distribution, and reproduction in any medium, provided you give appropriate credit to the original author(s) and the source, provide a link to the Creative Commons license, and indicate if changes were made. 


\section{Appendix A: EDS Analyses of the Solid Sample Obtained from SL (C) at Ethanol-to-Strip Liquor Volumetric Ratio of 0.8}

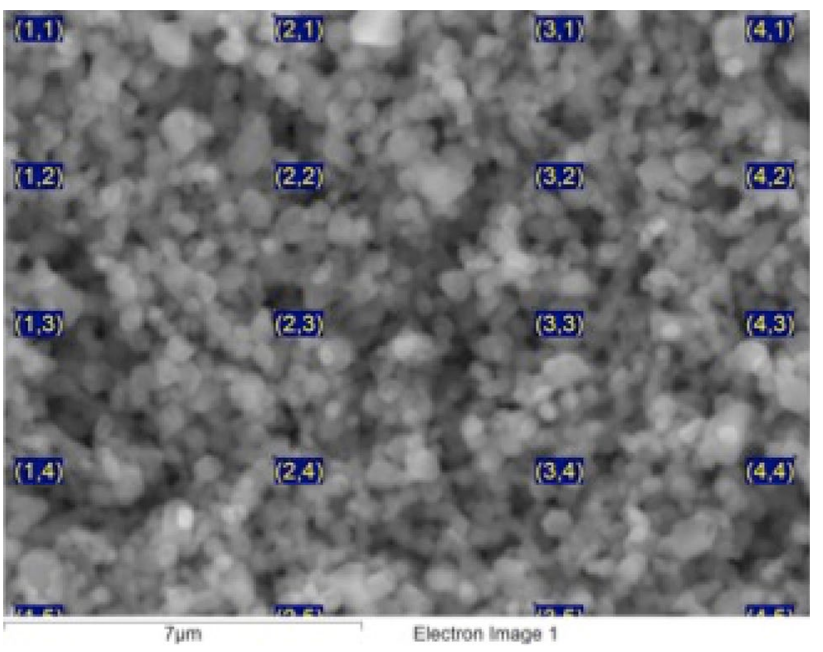

Processing option: all elements analyzed (Normalized)

\begin{tabular}{llllllr}
\hline Spectrum & N & F & Sc & Ti & Fe & Total \\
& wt $\%$ & & & & & \\
\hline$(1,1)$ & 13.80 & 49.88 & 34.91 & & 1.40 & 99.99 \\
$(2,1)$ & 14.82 & 59.05 & 25.19 & & 0.95 & 100.01 \\
$(3,1)$ & 14.68 & 56.68 & 27.10 & 0.49 & 1.05 & 100.00 \\
$(4,1)$ & 15.01 & 53.87 & 29.93 & & 1.18 & 99.99 \\
$(1,2)$ & 13.21 & 45.51 & 39.76 & & 1.53 & 100.01 \\
$(2,2)$ & 13.26 & 58.61 & 27.10 & & 1.04 & 100.01 \\
$(3,2)$ & 11.94 & 51.26 & 35.54 & & 1.26 & 100.00 \\
$(4,2)$ & 13.32 & 50.97 & 34.36 & & 1.36 & 100.00 \\
$(1,3)$ & 13.80 & 54.38 & 30.62 & & 1.20 & 100.00 \\
$(2,3)$ & 12.04 & 46.54 & 39.92 & & 1.50 & 100.00 \\
$(3,3)$ & 12.70 & 53.54 & 32.48 & & 1.30 & 100.01 \\
$(4,3)$ & 14.42 & 50.15 & 33.39 & 0.52 & 1.51 & 99.99 \\
$(1,4)$ & 14.65 & 59.14 & 25.27 & & 0.94 & 100.00 \\
$(2,4)$ & 13.51 & 57.36 & 28.02 & & 1.11 & 99.99 \\
$(3,4)$ & 13.87 & 55.86 & 29.30 & & 0.96 & 99.99 \\
$(4,4)$ & 13.89 & 54.00 & 30.95 & & 1.15 & 100.00 \\
$(1,5)$ & 16.56 & 59.89 & 22.70 & & 0.86 & 100.01 \\
$(2,5)$ & 15.45 & 61.31 & 22.39 & & 0.84 & 99.99 \\
$(3,5)$ & 14.04 & 55.37 & 29.53 & & 1.05 & 99.99 \\
$(4,5)$ & 13.99 & 53.07 & 31.22 & 0.37 & 1.35 & 100.00 \\
Average & 13.95 & 54.32 & 30.48 & 0.46 & 1.18 & \\
Max & 16.56 & 61.31 & 39.92 & 0.52 & 1.53 & \\
Min & 11.94 & 45.51 & 22.39 & 0.37 & 0.84 & \\
\hline & & & & & & \\
& & & & & & \\
& $13)$ & & & & &
\end{tabular}

\section{References}

1. Kaya Ş, Dittrich C, Stopic S, Friedrich B (2017) Concentration and Separation of Scandium from Ni Laterite Ore Processing Streams. Metals (Basel) 7:557. https://doi.org/10.3390/met71 20557

2. Binnemans K, Jones PT, Müller T, Yurramendi L (2018) Rare earths and the balance problem: how to deal with changing markets? J Sustain Metall 4:126-146. https://doi.org/10.1007/s4083 1-018-0162-8

3. Limited RIS (2015) By-product metals: Mastering these mysterious markets. In: Conference on Exchange of Good Practices on Metal By-product Recovery. Brussels

4. SRK Consulting, TetraTech, SMHProcessInnovation, et al (2017) Revised NI 43-101 Technical Report Feasibility Study Elk Creek Niobium Project Nebraska Revised NI 43-101 Technical Report Feasibility Study Elk Creek Niobium Project Nebraska

5. Habashi F (2013) Extractive metallurgy of rare earths. Can Metall Q 52:224-233. https://doi.org/10.1179/1879139513Y.00000 00081

6. Cotton SA (1999) Recent advances in the chemistry of scandium. Polyhedron 18:1691-1715. https://doi.org/10.2533/chimi a.2012.399

7. Krishnamurthy N, Gupta CK (2016) Extractive metallurgy of rare earths, 2nd edn. Taylor \& Francis, Milton Park

8. European Commission (2017) Communication from the commission to the European Parliament, the council, the European economic and social committee and the committee of the regions on the 2017 list of critical raw materials for the EU. Brussels

9. Magyar MJ, Petty TR (2018) Draft list of critical minerals. Fed Regist 83:7065-7068

10. Smirnov DI, Molchanova TV (1997) The investigation of sulphuric acid sorption recovery of scandium and uranium from the red mud of alumina production. Hydrometallurgy 45:249-259. https://doi.org/10.1016/S0304-386X(96)00070-9

11. Li D, Wang C (1998) Solvent extraction of Scandium(III) by Cyanex 923 and Cyanex 925. Hydrometallurgy 48:301-312. https://doi.org/10.1016/S0304-386X(97)00080-7

12. Myerson AS (2002) Handbook of industrial crystallization, 2nd edn. Butterworth-Heinemann, Boston

13. Alkan G, Yagmurlu B, Cakmakoglu S et al (2018) Novel approach for enhanced scandium and titanium leaching efficiency from bauxite residue with suppressed silica gel formation. Sci Rep 8:1-11. https://doi.org/10.1038/s41598-018-24077 $-9$

14. Borra CR, Pontikes Y, Binnemans K, Van Gerven T (2015) Leaching of rare earths from bauxite residue (red mud). Miner Eng 76:20-27. https://doi.org/10.1016/j.mineng.2015.01.005

15. Ochsenkühn-Petropoulou MT, Hatzilyberis KS, Mendrinos LN, Salmas CE (2002) Pilot-plant investigation of the leaching process for the recovery of scandium from red mud. Ind Eng Chem Res 41:5794-5801. https://doi.org/10.1021/ie011047b

16. Fujinaga K, Yoshimori M, Nakajima Y et al (2013) Separation of $\mathrm{Sc}(\mathrm{III})$ from $\mathrm{ZrO}$ (II) by solvent extraction using oxidized Phoslex DT-8. Hydrometallurgy 133:33-36. https://doi.org/10.1016/j. hydromet.2012.11.014

17. Ochsenkühn-Petropulu M, Lyberopulu T, Parissakis G (1995) Selective separation and determination of scandium from yttrium and lanthanides in red mud by a combined ion exchange/solvent extraction method. Anal Chim Acta 315:231-237. https://doi. org/10.1016/0003-2670(95)00309-N

18. Lash LD, Ross JR (1961) Vitro chemical recovers costly scandium from uranium solutions. Min Eng 967

19. Wang W, Pranolo Y, Cheng CY (2011) Metallurgical processes for scandium recovery from various resources: a review. 
Hydrometallurgy 108:100-108. https://doi.org/10.1016/j.hydro met.2011.03.001

20. Vickery RC (1955) The extraction and purification of scandium. J Chem Soc 245-251

21. Shaoquan X, Suqing L (1996) Review of the extractive metallurgy of scandium in China (1978-1991). Hydrometallurgy 42:337-343. https://doi.org/10.1016/0304-386X(95)00086-V

22. Martinez AM, Osen KS, Gudbrandsen H et al (2018) Direct method for producing scandium metal and scandium-aluminium intermetallic compounds from the oxides. In: Martin O (ed) Light Metals 2018. The Minerals Metals and Materials Society, Pittsburgh, pp 1559-1564

23. Rakov EG, Mel'nichenko EI (1984) The properties and reactions of ammonium fluorides. Russ Chem Rev 53:851-869. https://doi. org/10.1070/RC1984v053n09ABEH003126

24. Harata M, Nakamura T, Yakushiji H, Okabe TH (2008) Production of scandium and Al-Sc alloy by metallothermic reduction. Miner Process Extr Metall 117:95-99. https://doi.org/10.1179/17432 $8508 X 290876$

25. Yagmurlu B, Zhang W, Avdibegovic D, et al (2018) Advances on scandium recovery beyond state of the art. ALTA 2018 UraniumREE-Lithium Proc 85-93

26. Sokolova YV, Cherepanin RN (2011) Preparation and examination of the properties of complex scandium fluorides. Russ J Appl Chem 84:1319-1323. https://doi.org/10.1134/S10704272110800 40

27. Moldoveanu GA, Demopoulos GP (2015) Organic solvent-assisted crystallization of inorganic salts from acidic media. J Chem Technol Biotechnol 90:686-692. https://doi.org/10.1002/jctb.4355

28. Kury JW, Paul AD, Hepler LG, Connick RE (1959) The fluoride complexing of scandium(III) in aqueous solution: free energies, heats and entropies. J Am Soc 81:4185-4189

29. Mioduski T, Gumiński C, Zeng D (2014) IUPAC-NIST solubility data series. 100. Rare earth metal fluorides in water and aqueous systems. Part 1. Scandium Group (Sc, Y, La). J Phys Chem Ref Data. https://doi.org/10.1063/1.4866773

30. Potapenko SV, Rakov EG, Khaustov SV (1995) Solubility of scandium trifluoride and ammonium hexafluoroscandate in water and hydrofluoric acid. Russ J Inorg Chem 40:1073-1076

31. Sviridova TA, Sokolova YV, Pirozhenko KY (2013) Crystal structure of (NH4)5Sc3F14. Crystallogr Rep 58:220-225. https://doi. org/10.1134/S1063774513020272

32. Ivanov-Emin BN, Susanina TN, Ezhov AI (1967) Investigation of ammonium fluoroscandiates. Zh Neorg Khim 12:23-28

33. International Centre for Diffraction Data (2007) PDF-2 DIFFRACplus Reference Database

34. Kuhs M, Zeglinski J, Rasmuson ÅC (2014) Influence of history of solution in crystal nucleation of fenoxycarb: kinetics and mechanisms. Cryst Growth Des 14:905-915. https://doi.org/10.1021/ $\operatorname{cg} 4007795$

35. Nordström FL, Svärd M, Malmberg B, Rasmuson ÅC (2012) Influence of solution thermal and structural history on the nucleation of m-hydroxybenzoic acid polymorphs. Cryst Growth Des 12:4340-4348. https://doi.org/10.1021/cg3000312

36. Earnshaw A, Greenwood N (1985) Chemistry of the elements, 2nd edn. Elsevier, New York

37. Serre C, Corbière T, Lorentz C et al (2002) Hydrothermal synthesis of nanoporous metalofluorophosphates. 1. Precursor solutions of titanium fluoride and fluorophosphate in water, a 19F and 31P NMR study. Chem Mater 14:4939-4947

38. Peters E, Dittrich C, Kaya S, Forsberg K (2018) Crystallization of a pure scandium phase from solvent extraction strip liquors. In: Davis B et al. (ed) Extraction 2018, proceedings of the first global conference on extractive metallurgy, pp 2707-2713. Springer, New York 